\title{
Parental Care on Under Five Child Health Outcomes in Zimbabwe
}

\section{OPEN ACCESS}

Manuscript ID:

ECO-2021-09023594

Volume: 9

Issue: 2

Month: March

Year: 2021

P-ISSN: 2319-961X

E-ISSN: 2582-0192

Received: 14.12.2020

Accepted: 25.01.2021

Published: 01.03.2021

Citation:

Gamette, Pius, et al.

"Parental Care on Under

Five Child Health

Outcomes in Zimbabwe."

Shanlax International

Journal of Economics, vol. 9, no. 2, 2021, pp. 1-9.

DOI:

https://doi.org/10.34293/ economics.v9i2.3594

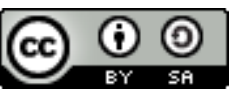

This work is licensed under a Creative Commons Attribution-ShareAlike 4.0 International License

\section{Pius Gamette}

Department of Economics, University of Cape Coast, Cape Coast, Ghana

D https://orcid.org/0000-0002-3448-3966

\author{
Refiloe Jabari \\ Department of Economics, University of Botswana, Gaborone, Botswana
}

\section{Sibusisiwe Bertha Muperere}

Department of Economics, University of Zimbabwe, Harare, Zimbabwe

\begin{abstract}
This study examines the effect of parental care on child health outcomes (stunting, wasting and underweight) in Zimbabwe. The study uses data from the Zimbabwe Demographic Health Survey (ZDHS) (1994-2015) by employing the Ordinary Least Method (OLS) regression approach. The results indicate that breastfeeding and vaccination on each count has a significant negative effect on under-five child health outcomes (stunting and wasting). On the contrary, child-size shows a significant positive effect on wasting and underweight among under-five children in Zimbabwe. Area of residence indicates an under five-child in an urban center is less likely to be wasting than its contemporary in a rural area. The individual effects of mothers' education, wealth index, child's sex and marital status show insignificant effects under-five child health outcomes. The policy implication is that health professionals should intensify education on early child suckling and succeeding dietary mix to obviate poor health outcomes. This study also implores the Ministry of Health and Child Care in Zimbabwe to review existing vaccination programmes by extending to households with poor child health outcomes found in inaccessible areas. As a contribution, this study provides a platform for deliberations on family care and child health care in African societies.
\end{abstract}

Keywords: Child health outcome, Anthropometric measures, Parental care, Demographic health survey, Zimbabwe

JEL Classification: I1, I3, I110, I120

\section{Introduction}

Efforts to improve child health outcomes continue to be a contemporary, pertinent and one of the most pressing issues in children's development. Hence, it has featured prominently among current world leaders discussions on global developmental targets, specifically the Millennium Development Goals (MDGs) and its successor, the Sustainable Development Goals (SDGs). This is against the backdrop that child nutritional status is an important outcome measure of children's health (NBS \& ICF Macro, 2011) however;, negative repercussions on children's wellbeing transcend beyond childhood (Lichter, 2007) and translate to a sick adult population.

Within the family setting, mothers play significant roles in influencing a child's health outcomes in their formative years. Given that mothers play critical roles in children's health, a large body of research dating back at least to the 1980s (e.g., Mechanic, 1980) has focused on maternal care behaviors that explain variations in a child's health outcomes. Prior health studies confirm that varied variables including health, psychological and social characteristics impact early health care services that mothers provide for their children. 
Specifically, mother's use of health services is predicted to have a positive association with their children's health care, reflecting similarities in health outcomes and patterns of helpseeking between generations (Broadhurst, 2003; Janicke, et al., 2001). Global health discussions have centered on under-five children since poor nutrition among such children reveals itself in anthropometric measures (underweight, stunting and wasting). These perspectives of nutrition and childhood diseases have attracted global public health concerns, especially in Sub-Saharan Africa.

Even though the African sub-region is regarded as one of the richest continents due to its large family sizes with numerous children, not many efforts have been made in achieving the SDG goal of improving child survival and development (United Nations, 2011). However, a systematic analysis of trends in stunting and underweight among children and the progress towards achieving the MDG 1, using data obtained from 141 developing countries, showed that moderate and severe stunting in children has declined from $47.2 \%$ to $29.9 \%$ between 1985 and 2011. According to Amsalu \& Tigabu (2008), the high incidence of child morbidity and mortality in developing countries is attributed to poor maternal care provided to children at their earlier and fragile years.

The advent of urbanization coupled with demanding job responsibilities has constrained mothers' efforts in providing child care; hence a high number of mothers shirk their responsibilities to either home care providers or other extended family members. Biological mothers continue to rely on childcare services provided by caregivers (nannies) and sometimes extended family members to cater to the health and physiological needs of children. However, meeting the health needs of children transcends beyond economic means. Caregivers and extended family members cannot provide holistic care that parents can offer children to grow well. This has resulted in most under-five children showing poor health outcomes (stunting, wasting and underweight).

Poor health outcomes among under-five children cut across many geographical jurisdictions in SSA, resulting from failure to provide adequate care for infantile groups. Health outcomes among under-five children in Zimbabwe are pronounced as reflected in the percentage of under-five children who exhibit poor health outcomes. There have been cases of child irregular food intake pattern, inappropriate child medication, child abuse and lack of physical activities for under-five children having a negative toll on children health outcomes.

Existing conceptual and empirical research on parental care predictor relationship and under-five children health outcomes have focused on either the effect of parent-child interaction of parental behaviors on child behavior. Schor (1995) indicated that the quality of interactions between a parent and child is key to developing quality time, empathy and strengthen intimate relationships. In the same vein, O'Connor \& Scott (2007) analyzed the extent to which parents who exhibit elevated rates of conflict and harsh parenting behaviors influence their children's behavior in exhibiting delinquent behaviors. Plantin (2001) also delved deep into fathers' active involvement in childcare and positively affected health outcomes for themselves, their partners and immediate offspring across Europe. Though these studies are revealing, the literature fails to employ survey data from a demographic health survey to analyze the effect of parental care on under-five children's health outcomes (stunting, wasting and overweight). It is against this background that the study uses data from the Zimbabwe Demographic Health Survey to analyze the effect of parental care on under-five child health outcomes. This study will test whether and the extent to which parental care influences under-five children's health outcomes. This is premised on the fact that the sort of parental care and its effect on under-five children's health outcomes only mostly gleaned from open discourse deprived of any pragmatic content.

The rest of the paper is organized as follows. Section 2 presents a review of the literature (theoretical) and empirical evidence on child health outcomes. Section 3 deals with research methods(estimation technique, data source and variables description). The results and discussion are presented in Section 4 and section 5 concludes the paper with gaps and conclusion. 


\section{Review of Literature}

\section{Child Health Outcomes}

Disparities in child health outcomes persist across the globe despite several attempts to improve the well-being of children. Various epidemiological studies have identified that variations in factors that determine child health outcomes across various contexts explain the variations in child health outcomes. Several theories and conceptual frameworks have also been developed to explain these variations. The survival of a child in the first and subsequent weeks and years depends on several socioeconomic, biological, environmental and cultural factors (Venkatacharya and Tesfay, 1986).

Chakraborty (2005) highlighted that the most prominent causes of variations in child health outcomes are levels of poverty, parental education, nutrition, and environment of residence. In instances of poor households (families), the mother is less likely to afford healthcare for infant $\&$ in some instances, delivers at home such that infant is not likely to be vaccinated. Ogada (2012) argues that a mother's education is important in allowing her to make sound choices regarding the child's health \& seeking out healthcare \& understanding importance of adhering to vaccination requirements for instance.

\section{Ecological System Theory}

Urie Bronfenbrenner (2005) also developed an ecological system theory to explain how a child's environment affects how a child grows and develops. The ecological theory postulates that the child health outcome is a result of the interaction of the child's macro, micro and ecosystems where the macro system is made up of factors such as relative freedoms permitted by the national government, cultural values, the economy, wars, etc. which can affect a child either positively or negatively. The microsystem is composed of the immediate relationships or organizations they interact with, such as their immediate family or caregivers and their school or daycare. Under this framework, parental care also plays a key role as a factor influencing child health. The ecosystem is made up of the environment that the child rarely interacts with but has a huge influence of the child's development. Such factors may include the state of the neighborhood and extended family as these have an indirect impact on the quality of care and attention provided to the child.

Mosley and Chen (1984) developed a framework for child health using child mortality/survival as an indicator of child health. The framework postulates that all social and economic determinants of child mortality necessarily operate through a common set of biological mechanisms or proximate determinants (intermediate variables) to influence the chances of survival directly. Maternal factors such as age, parity and birth interval have been shown to exert an independent influence on pregnancy outcome and infant survival through their effects on maternal health.

The mother's health and nutritional status as well as her reproductive pattern, influence the health and survival, allowing for a longer duration of breastfeeding which in turn feeds into the child's health outcomes during pregnancy as well as in the infancy years. Environmental factors also affected child mortality or child survival such that children born in environments where conditions are good and well taken care of surviving more than those born in deplorable environments like slum areas of urban centers where contamination of the environment, lack of quality water for domestic use and limited toilet facilities are a characteristic. The socioeconomic determinants (independent variables) operate through the proximate determinants to influence the level of growth faltering and mortality.

\section{Empirical Literature}

It has emerged from cross-country comparisons that mother's education (Caldwell 1979, Mensch et al., 1983; Simmons \& Bernstein, 1982) and together with the work of other studies, have established a correlation between variables such as literacy, mother's place of residence and expenditure on health and infant and child mortality. Empirically, vaccination has been associated with improved health outcomes across the world (Mondal 2009; Zwedu, 2010; Eiselle et al., 2012; Fischer \& Walker 2014). Other factors such as personal hygiene of the mother and child, toilet facilities, safe water supply and prevalence of diseases in the environment also influence child survival. 
In developing countries, background characteristics such as mother's literacy, urban or rural residence and household economic status are likely to affect a child's condition at birth as well as its environment, thus affecting infant and child mortality (Hobcraft et al., 1984; Mosley and Chen, 1984; United Nations, 1985). A study done by Baker (1999) and Espo (2002) in Zambia revealed that the age of the mother and the breastfeeding duration was significant in reducing child health mortality and consequently improvement of health. Other studies were done in developing countries such as Vietnam, Malawi and India have also confirmed that children weaned early. Previous studies also revealed that vaccination plays a pivotal role in improving health outcomes, as posited by studies by Mondal (2009); Babale (2013); Kiyen et al. (2010) and Guerera (2013) and Chizoba et al. (2013) found a positive correlation between immunization and child health outcomes.

\section{Research Methods \\ Estimation Strategy}

The researchers adopted the Cobb-Douglass production function in which output $(\mathrm{Y})$ is determined by two factors, capital (K) and labor (L), as laid out in Solow's model (Cobb \& Douglas, 1928). Defining output per worker (y) and capital per worker (k), the production function takes the following form:

$$
\mathrm{Y}=\mathrm{f}\left(\mathrm{K}_{\mathrm{t}}, \mathrm{L}_{\mathrm{t}}\right)
$$

Based on theoretical and empirical evidence, the paper captures some variables that affect child health outcomes in Zimbabwe as follows:

$H O=f\left(B F_{t}, V C_{t}, W_{t}, S E X_{t}, C S_{t}, M_{t}, M_{t}, M E_{t}\right.$, $\mathrm{WS}_{\mathrm{t}}, \mathrm{R}_{\mathrm{t}}$ )

Where $\mathrm{HO}$ is the health outcomes (stunting, wasting and underweight), $\mathrm{BF}$ is Breastfeeding, $\mathrm{VC}$ is vaccination, $\mathrm{W}$ is wealth, SEX is the sex of the child, CS is the child-size, MS is the mother's marital status, MA is the mother's age, ME is the mother's educational level, WS is the household water source and $\mathrm{R}$ is the residence.

By applying the Ordinary Least Square (OLS), we derive equation (3)

$$
\begin{array}{r}
\mathrm{HO}_{\mathrm{t}}=\alpha_{\mathrm{i}}+\beta_{1} \mathrm{BF}_{\mathrm{t}}+\beta_{2} \mathrm{VC}_{\mathrm{t}}+\beta_{3} \mathrm{~W}_{\mathrm{t}}+\beta_{4} \mathrm{SEX}_{\mathrm{t}}+\beta_{5} \mathrm{CS}_{\mathrm{t}} \\
+\beta_{6} \mathrm{MS}_{\mathrm{t}}+\beta_{7} \mathrm{MA}_{\mathrm{t}}+\beta_{8} \mathrm{ME}_{\mathrm{t}}+\beta_{9} \mathrm{WS}_{\mathrm{t}}+\beta_{10} \mathrm{R}_{\mathrm{t}}+\mathrm{e}_{\mathrm{t}}
\end{array}
$$

\section{Data Source}

This study uses data derived from five Zimbabwe Demographic and Health Surveys (ZDHS). The various demographic and health surveys were conducted at irregular intervals. Data from the 1994, 1999, 2005, 2010 and 2015 ZDHS provide the background and framework for trends in households' health outcomes. The ZDHS is a nationally representative survey of health, demographic and other allied issues important to development, conducted among women age 15-49 and men age 15-54. The household member and children's recode datasets are merged and used for analysis. The household member dataset represents background information on all members of the household, while the children's dataset gives information on children under the age of five of interviewed women.

\section{Measurement of Key Variables}

This study adopts the UNICEF (1990) model for studying malnutrition to investigate three dimensions of child health outcomes, height-forage (stunting), weight-for-height(underweight) and weight-for-age (wasting). According to the model, nutritional status is the outcome of the interplay among basic, underlying and immediate factors. The basic factors consist of structural characteristics - region and urban-rural residence and background (remote) - and household characteristics - wealth index and sources of drinking water - and maternal characteristics - education, marital status and age. These indirectly influence the underlying factors of child-related variables and directly influence the immediate factors that lead to nutritional status.

Table 1: Measurement of Variables

\begin{tabular}{|l|l|}
\hline \multicolumn{1}{|c|}{ Variable } & \multicolumn{1}{c|}{ Measurement/units } \\
\hline $\begin{array}{l}\text { Height-for-agez- } \\
\text { score }\end{array}$ & $\begin{array}{l}\text { (Child's height-median of ref. } \\
\text { group) / SD of ref. group }\end{array}$ \\
\hline $\begin{array}{l}\text { Weight for- } \\
\text { heightz-score }\end{array}$ & $\begin{array}{l}\text { (Child's weight-median of ref. } \\
\text { group) / SD of ref. group (same } \\
\text { height) }\end{array}$ \\
\hline $\begin{array}{l}\text { Weight-for-age } \\
\text { z-score }\end{array}$ & $\begin{array}{l}\text { Child's weight-median of ref. } \\
\text { group) / SD of ref. group }\end{array}$ \\
\hline Breastfeeding & $\begin{array}{l}\text { Duration of breastfeeding in } \\
\text { months }\end{array}$ \\
\hline Vaccination & A child ever had a vaccination \\
\hline
\end{tabular}




\begin{tabular}{|l|l|}
\hline Sex of child & A child ever had a vaccination \\
\hline $\begin{array}{l}\text { Child's size at } \\
\text { birth }\end{array}$ & $\begin{array}{l}\text { A proxy for initial health status } \\
\text { Very large }=1 ; \text { average }=2\end{array}$ \\
\hline Wealth index & Asset index \\
\hline Mother's age & $\begin{array}{l}\text { Mother's age captured as } \\
\text { completed years }\end{array}$ \\
\hline $\begin{array}{l}\text { Mother's } \\
\text { educational level }\end{array}$ & $\begin{array}{l}\text { No education }=0 ; \text { primary }=1 ; \\
\text { secondary }=2 ; \text { higher }=3\end{array}$ \\
\hline $\begin{array}{l}\text { Mother's marital } \\
\text { status }\end{array}$ & $\begin{array}{l}\text { Never married }=1 ; \text { currently } \\
\text { married }=2\end{array}$ \\
\hline $\begin{array}{l}\text { Household } \\
\text { source of water }\end{array}$ & Pipe/bottled water $=1 ;$ other $=0$ \\
\hline Residence & Rural $=0 ;$ urban $=1$ \\
\hline
\end{tabular}

Source: Gamette et al. (2020)

\section{Description of Variables \\ Child Health Outcomes}

Child health outcomes are measured using anthropometric indicators of height-for-age, weightfor-height and weight-for-age. The indicators are captured as z-scores with values in the range of \pm 6 and thresholds for classifying nutritional status (WHO, 2006). Children with z-scores less than -2 for height-for-age, weight-for-height and weight-forage are classified, respectively, as stunted, wasted or underweight. Stunting is a measure of chronic malnourishment, whereas wasting is a measure of acute malnourishment, and underweight reflects both acute and chronic under nutrition. In this paper, the classifications are used for the inferential analysis.

\section{Breast-Feeding}

This variable is used as a proxy for the mother's care on child health outcome. It is measured as several months at which the mother has breastfed the child. Exclusive breastfeeding reduces infant mortality due to common childhood illnesses such as diarrhea or pneumonia and helps for a quicker recovery during illness. We expect the negative relationship between breast-feeding and all the anthropometric measures.

\section{Vaccination}

The percentage of children who receive specific vaccines according to vaccination card. It is expected that vaccination will hurt child health outcomes.

\section{Mother's Education}

The more-educated mother may be better informed about the availability and use of health care or have better health behavior that confers benefits to their children. We expect a negative relationship between mother's education and child health outcomes used in this study.

\section{Wealth Index}

It is a composite measure of a household's cumulative living standard. The wealth index is calculated using data on households' ownership of selected assets and types of water access and sanitation facilities. Wealthier households can allocate more resources to other goods (such as better food or cleaner home environments) that improve health, so the wealth index is expected to negatively affect the anthropometric measures.

\section{Results and Discussion}

The trend of Health Outcomes of under five-year children in Zimbabwe (1994-2015).

\section{Figure 1: Trend of Health Outcomes Dimensions} - Stunting, Underweight and Wasting of under five children in Zimbabwe (1994-2015)

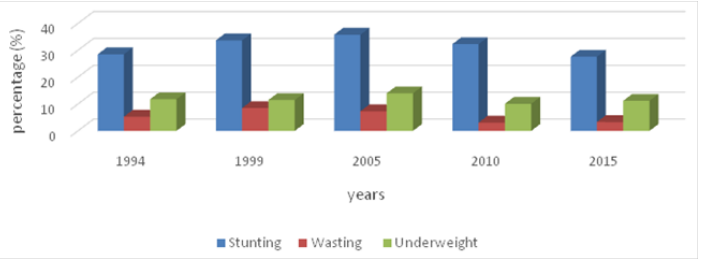

Source: Gamette et al. (2020)

From figure 1 above, all the anthropometric measures (stunting, wasting and underweight) among under-five children show increasing trends with each reaching a maximum and eventually begins to show a downward trend. It also shows that stunting among children under five years in Zimbabwe was highest (35.8\%) in 2005. Underweight and wasting got to their peaks at $11.8 \%,(1994)$ and $8.5 \%$ (1999) respectively. On the other hand, stunting, wasting and underweight have their lowest recorded values at $27.6 \%$ (2015), 3.1\% (2010), and10.1\% (2010), respectively.

Moreover, these anthropometric indicators vary from one geographical to another. Stunting levels 
vary geographically from 19 percent in Bulawayo province to 31 percent in Matabeleland South and are higher in rural areas (29 percent) than urban areas (22 percent). Differences in stunting levels can also be attributed to maternal education and wealth levels - 25 percent of children whose mothers have a secondary education are stunted. In comparison, the prevalence rises to 45 percent of children whose mothers had no formal education.
At 6 percent, the prevalence of thinness among women 15-49 years has reduced slightly since 2010-2011 (ZNSA and ICF, 2016). Poor infant and young child feeding practices contribute to child malnutrition in Zimbabwe. Moreover, exclusive breastfeeding prevalence further decreases to only 20 percent among children 4-5 months. Among children 6-23 months, only 10 percent are fed a minimally acceptable diet appropriate frequency and diversity.

\section{Effects of Mother's Care on Child Health Outcomes in 2015}

Table 2: Linear Regression Results of the Relationship between Child Health Outcomes and Breastfeeding, Vaccination and Other Covariates, Zimbabwe 2015

\begin{tabular}{|c|c|c|c|c|c|c|}
\hline \multirow{2}{*}{ Explanatory Variable } & \multicolumn{2}{|c|}{ Stunting } & \multicolumn{2}{|c|}{ Wasting } & \multicolumn{2}{|c|}{ Underweight } \\
\hline & Coeff. & t-statistic & Coeff. & t-statistic & Coeff. & t-statistic \\
\hline Breastfeeding & $-0.139747 *$ & $(-2.47)$ & $-.0604403 *$ & $(-2.00)$ & -.0350252 & $(-1.58)$ \\
\hline Vaccination & $-0.039592 *$ & $(-2.53)$ & $-.0577664 *$ & $(-1.91)$ & -.0344726 & $(-1.56)$ \\
\hline Wealth index & .0021425 & $(0.13)$ & -.2125778 & $(-1.75)$ & -.0174516 & $(-0.20)$ \\
\hline Male child & -.0170193 & $(-1.75)$ & -.0946465 & $(-1.35)$ & .0166324 & $(0.32)$ \\
\hline Child's size at birth (average) & .0328698 & $(1.82)$ & $.2898703 *$ & $(2.24)$ & $.2408098^{*}$ & $(2.54)$ \\
\hline Marital Status & .0033113 & $(0.13)$ & .2858911 & $(1.56)$ & .0211066 & $(0.16)$ \\
\hline Mother's age & -.001068 & $(-1.29)$ & -.0007373 & $(-0.12)$ & -.0059854 & $(-1.37)$ \\
\hline Mother's education (primary) & -.0401229 & $(-0.83)$ & .0377083 & $(0.11)$ & .1090957 & $(0.43)$ \\
\hline Mother's education (secondary) & -.0443932 & $(-0.92)$ & .1178355 & $(0.34)$ & .0762019 & $(0.30)$ \\
\hline Mother's education (Higher) & -.0068888 & $(-0.13)$ & .0474339 & $(0.12)$ & -.0487399 & $(-0.17)$ \\
\hline Household source of water & -.0006682 & $(-0.15)$ & .0098215 & $(0.31)$ & -.005755 & $(-0.25)$ \\
\hline Urban residence & .0180278 & $(0.80)$ & $-.332715^{*}$ & $(-2.05)$ & -.0091236 & $(-0.08)$ \\
\hline Constant & -.9597188 & $(-1.24)$ & -11.04355 & $(-1.99)$ & -5.564789 & $(-1.36)$ \\
\hline $\mathrm{N}$ & 678 & & 678 & & 678 & \\
\hline $\mathrm{R}^{2}$ & 0.0409 & & 0.0237 & & 0.0165 & \\
\hline F-statistics & $\begin{array}{c}3.99 \\
(0.0000)\end{array}$ & & $\begin{array}{c}2.27 \\
(0.0001)\end{array}$ & & $\begin{array}{c}1.57 \\
(0.0199)\end{array}$ & \\
\hline
\end{tabular}

Reference groups: no education; rural residence; ${ }^{*} \mathrm{p}<0.10 ;{ }^{* *} \mathrm{p}<0.05 ;{ }^{* * *} \mathrm{p}<0.01$.

The results from table 2 show that breastfeeding significantly affects stunting and wasting but does not influence the underweight of a child. An increase in months of breastfeeding would reduce stunting and waste by 0.13 and 0.06 , respectively. These results are in line with our expectations. Breast milk is the natural first food for babies. It provides all the energy and nutrients that the infant needs for the first months of life and it continues to provide up to half or more of a child's nutritional needs during the second half of the first year and up to one-third during the second year of life (WHO, 2006). Vaccination also has a significant negative effect on stunting and wasting but does not influence the underweight. The results are consistent with findings from studies (Mondal, 2009; Eiselle et al., 2012; Fischer \& Walker, 2014), indicating vaccination has a significant influence in determining child health outcomes.

Child size, a proxy for health status at birth, shows a significant positive effect on wasting and overweight among under-five children in Zimbabwe. Specifically, under-five children with average size are 0.2898703 and 0.2408098 more likely to showing acute malnutrition symptoms (wasting) and chronic 
malnutrition symptoms (underweight) comparable to an under-five child who is very large at birth. Residential area (urban) was discovered to hurt under-five at a $10 \%$ significance level. Intuitively, an under-five child in urban areas has 0.332715 less showing acute malnutrition symptoms (wasting) than their rural areas. This is consistent with the findings of Hobcraft et al. (1984), suggesting residential space affects infant and child health outcomes. Wealth, child's sex, marital status, mother's age, mother's education and household source of water have no significant impact on all the three child health outcomes in Zimbabwe.

\section{Research Gap \& Conclusion}

The aim of this study was to examine the effect of parental care on under-five child health outcomes in Zimbabwe. The child health outcome is a continuous variable measured with three anthropometric indicators; weight-for-height (wasting), height-forage (stunting) and weight-for-age (underweight). This paper showed the trends in child health outcomes in 1994-2015 and examined the effect of parental care on under-five child health outcomes in Zimbabwe. Understanding the factors and channels that influence child health outcomes has become important given the short-term and long-term implications of good health, both for individuals and national development (Black et al., 2013). Breastfeeding as a proxy for a mother's care was significant in determining the child's health outcome. An increase in months of breastfeeding reduces stunting and wasting. Vaccination and child size at birth are also significant in influencing the anthropometric measures. An under-five child with average body size at birth was more susceptible to showing symptoms of wasting and underweight than a child with very large body size at birth. The residential place played a significant role in determining under-five child health care in Zimbabwe. Specifically, under-five in urban areas had better health outcomes than their counterparts in the rural areas.

\section{Policy Implications}

In terms of the policy, the article suggests that to improve the health outcomes of under-five children, health professionals should intensify nutritional education on breastfeeding. This will inform mothers on the need to breastfeed their child during formative years, especially for at least six months. Moreover, the Ministry of Health and Child Care in Zimbabwe should revise current vaccination strategies and expand vaccination programs targeting more remote areas.

\section{Limitation of the Study}

The key limitation of this study was that all information was obtained from survey data. Measures related to parental care (mother's care) and child health outcomes were mother-reported, which could result in self-report bias because of social desirability related to being a caring mother. However, because data was not available for male parents, future studies could also include male parents. Despite the data limitation, the findings from this study could still be counted on in the quest to improve under-five year health outcomes. The researcher proposed that future studies on this subject matter can concentrate on a comparative study based on SSA sub-regions.

\section{Acknowledgment}

The authors are grateful to anonymous referees for their extremely useful suggestions to improve the quality of the article. We also acknowledge useful contributions from the faculty of the Africa Economic Research Consortium (AERC). However, the usual disclaimers apply.

\section{Declaration of Conflicting Interests}

The author(s) declared no potential conflicts of interest concerning the research, authorship and publication of this article.

\section{Availability of Data and Materials}

The full dataset supporting the conclusions of this article is available upon request.

\section{Ethics Approval and Consent to Participate Not applicable.}

\section{Consent for Publication}

Not applicable. 


\section{Funding}

The author(s) received financial support from the Africa Economic Research Consortium (AERC) for the research and authorship of this article.

\section{References}

Baker, Ria. "Differential in Child Mortality in Malawi." Social Networks Project Working Papers No. 3, 1999.

Bbaale, Edward. "Factors Influencing Childhood Immunization in Uganda." Journal of Health, Population and Nutrition, vol. 31, 2013, pp. 118-129.

Black, Robert E., et al. "Maternal and Child Undernutrition and Overweight in LowIncome and Middle-Income Countries." Lancet, vol. 382, 2013, pp. 427-451.

Bronfenbrenner, Urie. "Ecological Models for Human Development." International Encyclopedia of Education, 1994.

Caldwell, J.C. "Education as a Factor of Mortality Decline An Examination of Nigerian Data." Population Studies, vol. 33, no. 3, 1979, pp. 395-413.

Chakraborty, Priyanka. Determinants of Nutritional Status in Children under 5 Years in India: A Multilevel Approach, University of Calcutta, 2001.

Demographic and Health Survey Report 2015, Zimbabwe National Statistics Agency, 2015.

Espo, Merimaaria. Infant Mortality and its Underlying Determinants in Rural Malawi. University of Tampere, 2002.

Guerrera, Giacomo. "Neonatal and Pediatric Health Care Worldwide: A Report from UNICEF." Clinica Chimica Acta, vol. 451, 2015

Hobcraft, J.N., et al. "Socio-economic Factors in Infant and Child Mortality: A Cross-national Comparison." Population Studies, vol. 38, no. 2, 1984, pp. 193-223.
Lichter, Daniel T. Marriage as Public Policy. Policy Report, 2001.

Mechanic, David. "The Experience and Reporting of Common Physical Complaints." Journal of Health and Social Behavior, vol. 21, no. 2, 1980, pp. 146-155.

Mensch, B., et al. "Comparative Patterns of Child Mortality Differentials in Developing Countries." Annual Meetings of the Population Association of America, 1983.

O'connor, Thomas, and Stephen B.C. Scott. Parenting and Outcomes for children, Joseph Rowntree Foundation, 2007.

Schor, Edward L. "The Influence of Families on Child Health: Family Behaviors and Child Outcomes." Pediatric Clinics of North America, vol. 42, no. 1, 1995, pp. 89-102.

Strategy for Improved Nutrition of Children and Women in Developing Countries, UNICEF, 1990.

Tanzania Demographic and Health Survey 2010, 2011.

Teklu, T., and K. Venkatacharya. "Estimation of Infant and Child Mortality in Africa: Recent Experiences." World Fertility Survey Regional Review Seminar, 1986, pp. 17-21.

Walker, Christa L Fischer, and Neff Walker. "The Life Saved Tool as a Model for Diarrhoea Mortality Reduction." BMC Medicine, vol. 12, 2014.

WHO Child Growth Standards: Length/Height-forAge, Weight-for-Age, Weight-for-Length, Weight-for-Height, and Body Mass Indexfor-Age: Methods and Development, World Health Organization, 2006.

Wonodi, Chizoba B., et al. "Evaluation of Risk Factors for Severe Pneumonian Children: The Pneumonia Etiology Research for Child Health Study." Clinical Infectious Disease, vol. 54, 2013, pp. 124-131. 


\section{Appendix}

Appendix A: Summary Statistics of Variables used for Inferential Statistics

\begin{tabular}{|l|c|c|c|c|c|}
\hline \multicolumn{1}{|c|}{ Variable } & Obs & Mean & Std. Dev. & Min & Max \\
\hline Stunting & 3125.00 & 0.02 & 0.42 & -5.67 & 4.45 \\
\hline Wasting & 3125.00 & 0.13 & 1.98 & -5.98 & 5.96 \\
\hline Underweight & 3125.00 & 0.37 & 1.47 & -5.94 & 5.89 \\
\hline Vaccination & 3125.00 & 92.01 & 0.63 & 92.00 & 94.00 \\
\hline Age of Child & 3125.00 & 34.58 & 14.05 & 1.00 & 59.00 \\
\hline Breast feeding & 3125.00 & 93.32 & 0.72 & 93.00 & 95.00 \\
\hline Child size & 3125.00 & 2.74 & 0.92 & 1.00 & 5.00 \\
\hline Wealth index & 3125.00 & 3.05 & 1.44 & 1.00 & 5.00 \\
\hline Mother's age & 3125.00 & 29.32 & 6.51 & 16.00 & 49.00 \\
\hline Mother's educational level & 3125.00 & 1.73 & 0.57 & 0.00 & 3.00 \\
\hline Marital status & 3125.00 & 1.25 & 0.94 & 0.00 & 5.00 \\
\hline Household water source & 3125.00 & 23.26 & 10.90 & 11.00 & 96.00 \\
\hline Residence & 3125.00 & 1.63 & 0.48 & 1.00 & 2.00 \\
\hline
\end{tabular}

Source: Gamette et al., 2020

\section{Author Details}

Pius Gamette, Department of Economics, University of Cape Coast, Cape Coast, Ghana,

EmailID: gamettepius@gmail.com

Refiloe Jabari, Department of Economics, University of Botswana, Gaborone, Botswana

Sibusisiwe Bertha Muperere, Department of Economics, University of Zimbabwe, Harare, Zimbabwe 